\title{
Escola do mundo: ideias para adiar o fim da arte, do bairro (Gamboa) e do mundo ${ }^{1}$
}

\section{School of the World: Ideas to Postpone the End of Art, of the Neighborhood (Gamboa) and of the World}

\author{
Escuela del mundo: ideas para posponer \\ el fin del arte, del barrio (Gamboa) y del mundo
}

Luiz Guilherme Vergara (Universidade Federal Fluminense, Brasil) ${ }^{2}$

Kriss Coiffeur (Bar Delas, Rio de Janeiro, Brasil) ${ }^{3}$

Ligia Veiga (Grande Companhia de Mysterios e Novidades, Brasil) ${ }^{4}$

Thelma Vilas Boas (Lanchonete <> Lanchonete e Escola Por Vir, Brasil) ${ }^{5}$

https://doi.org/10.22409/poiesis.v20i34.40099

RESUMO: No dia 16 de outubro reunimos um grupo de estudantes de graduação em artes da UFF para uma visita aos projetos Lanchonete $<>$ Lanchonete (Bar Delas), Escola Por Vir e a Grande Companhia de Mysterios e Novidades, Escola Sem Parede, todos no Bairro da Gamboa. O impacto dos depoimentos da Kriss Coiffeur, Ligia Veiga e Thelma Vilas Boas, juntamente com a riqueza cultural destes cenários urbanos, atravessou os palimpsestos e anacronismos de diferentes camadas históricas, políticas e econômicas, apontando para práticas de resistência e resiliências das ações coletivas e solidárias. Esta imprevisível aula aberta reuniu "ideias e visões", se apropriando do sentido de adiar o fim do mundo de Ailton Krenak, ideias de escolas de arte para adiar o fim do bairro da Gamboa ou do papel da arte no mundo.

PALAVRAS-CHAVE: escolas de arte; Gamboa; gentrificação 
ABSTRACT: On October $16^{\text {th }}, 2019$. we gathered a group of UFF undergraduate students in arts for a visit to the projects Lanchonete <> Lanchonete (Bar Delas), the Upcoming School and the Great Company of Mysterios and Novelties, School Without Walls, in neighborhood of Gamboa. The impact of the testimonies of Kriss Coiffeur, Ligia Veiga and Thelma Vilas Boas, together with the cultural richness of these urban scenarios, crossed the palimpsests and anachronisms of different historical, political and economic layers, pointing to practices of resistance and resilience of collective and solidarity actions. This unpredictable open class brought together pragmatic "ideas and visions" to appropriate Ailton Krenak's "ideas to postpone the end of the world", or being more specific, or at least, or ideas of art schools to postpone the end of the neighborhood of Gamboa, or the role of art in the world.

KEYWORDS: art schools; Gamboa; gentrification

RESUMEN: El 16 de octubre nos reunimos un grupo de estudiantes graduados en el arte UFF para una visita a proyectos Lanchonete $<>$ Lanchonete (Bar Delas), Escuela para venir y la Grande Companhia de Mysterios e Novidades, la Escuela sin pared, el Distrito Gamboa. El impacto de los testimonios de Kriss Coiffeur, Ligia Veiga y Thelma Vilas Boas, junto con la riqueza cultural de estos escenarios urbanos, cruzó los palimpsests y anacronismos de diferentes capas históricas, políticas y económicas, apuntando a las prácticas de resistencia y la resistencia de las acciones colectivas y solidarias. Esta clase abierta se reunió impredecible "ideas y visiones," apropiarse el sentido de posponer el fin del mundo de Ailton Krenak, ideas de escuelas de arte para posponer el final del barrio Gamboa o el fin del papel del arte en el mundo.

PALABRAS CLAVE: escuelas de arte; Gamboa; gentrificación

Citação recomendada:

VERGARA, Luiz Guilherme; COIFFEUR, Kriss; VEIGA, Ligia; VILAS BOAS, Thelma. Escola do mundo: ideias para adiar o fim da arte, do bairro (Gamboa) e do mundo. Poiésis, Niterói, $v$. 20, n. 34, p. 233-260, jul./dez. 2019. [https://doi.org/10.22409/poiesis.v20i34.40099]

Luiz Guilherme Vergara, Kriss Coiffeur, Ligia Veiga, Thelma Vilas Boas. Escola do mundo: ideias para adiar... 


\section{Escola do mundo: ideias para adiar o fim da arte, do bairro (Gamboa) e do mundo}

\section{Introdução}

Três mulheres, Kriss Coiffeur, Ligia Veiga e Thelma Vilas Boas, três vidas, três projetos - Lanchonete (Bar Delas), Escola Por Vir e a Grande Companhia de Mysterios e Novidades / Escola sem paredes, conduzidas pela solidariedade, atravessam as categorias, circuitos e sistemas instituídos da arte, sejam as faculdades, escolas ou museus e galerias, todas compondo um tecido de sinergias na Gamboa. O que Thelma toma de Davi Kopenawa (A queda do céu) como por vir diante de colapsos emerge em sua fala e ação pelo sentido existencial, social e pedagógico constituintes do agir no futuro pelas crianças. Ou como Ligia celebra em seu quadro-negro de fundamentos para de uma Escola sem paredes - "somos o sonho de nossos ancestrais." Em todas essas trajetórias, a CORAGEM é presente como agir do coração. Entre as crianças do bairro que cruzam o Bar Delas, a Lanchonete e agora a Escola do Por Vir, fruto da colaboração entre Thelma e Kriss, têm-se também na mesma vizinhança a trajetória de uma es- 
cola de arte (desde 2007) voltada aos cortejos, ao teatro de rua, incorporando todos os santos aos moradores de rua. O que se testemunha nessas vozes é a resistência e a necessidade vital da arte para gerar "ideias para adiar" o futuro que traz colapsos, o fim do mundo, o fim de um bairro ameaçado pela trilhos da gentrificação, do tráfego e das milícias da Zona Portuária.

As falas gravadas, acompanhadas pelos registros fotográficos realizados pelxs próprixs estudantes, foram constantemente cortadas pelos sinos e signos da passagem do VLT (Veículo Leve de Transporte). Levemente nostálgico, insistentemente marcante do atravessamento e da chegada de um mundo de incertezas do que vêm, e se transporta de uma complexidade inquietante de indagações. O que pode ainda ser adiado, ou transformado, pelos exercícios diários de solidariedade? Pode a potência e fragilidade das microgeografias de afetos fundar uma escola-abrigo-floresta da arte para adiamentos dos colapsos? Visitam-se nessas falas e percursos de vida uma geografia de inquietações que não apenas compõem as reconfigurações existenciais de cada uma dessas protagonistas, mas também as mudanças em esboço para os sentidos de luta e transformação que atingem as faculdades e escolas de arte sem paredes e com florestas.

Depois de 40 anos como moradora e liderança das ocupações na Gamboa, Kriss Coiffeur resolveu fazer faculdade em Ciências Sociais, sob a influência ou inspiração de Thelma Vilas Boas. Ligia Veiga é um patrimônio vivo de uma geração de guerrilha, formada fora da faculdade por mestres como Hélio Eichbauer (1941-2018) e Graciela Figueroa (Uruguai, 1944), cruzando os anos de Rubens Gerchman na Escola de Artes Visuais do Parque Lage e as experiências com o grupo Coringa no MAM. Apesar da ditadura militar, Ligia conta sua trajetória através dos anos 70 pelas lutas e experiências de liberdade da arte e do teatro de rua como sua verdadeira escola, que vão fundamentar as bases da Grande Companhia de Mysterios e Novidades criada em São Paulo em 1981, até sua chegada à Gamboa em 2007. A Grande Companhia de Mysterios e Novidades migra para Zona Portuária como Escola sem paredes, inicialmente pelo Projeto "Gigantes pela própria Natureza" - orquestra itinerante sobre pernas de pau. Sem dúvida, Ligia projetava uma escola floresta de imaginários voltada para a formação de

Luiz Guilherme Vergara, Kriss Coiffeur, Ligia Veiga, Thelma Vilas Boas. Escola do mundo: ideias para adiar... 
jovens que atuariam em uma "orquestra de perna de pau", para produção de cortejos, rituais, teatro e ações de rua, como tal, uma visão de arte pública para além das faculdades.

Ao mesmo tempo em que a cartografia dessas confluências entre arte e vida aponta também para desobediências e resistências epistêmicas e ontológicas de transformações e cuidados existenciais, sociais e políticos, a própria reconfiguração urgente do sentido de escola de arte é colocada em questão. Esses relatos inspiram prospecções e indagações sobre os fundamentos éticos do pragmatismo utópico como linhas micropolíticas e geopoéticas para adiar o fim da arte, do bairro e do mundo. O pragmatismo utópico se traduz como sentido público da arte, indissociável das inquietações e incompletudes existenciais formando um tecido imantado de atração de indivíduos como agentes e agenciamentos do por vir como forma e potência para a vontade construtiva coletiva do comum, de comunidades e escolas experimentais de solidariedade.

\section{Primeiro encontro com Kriss Coiffeur}

\section{- Bar Delas / Lanchonete <> Lanchonete}

A trajetória de vida de uma liderança comunitária pode ser contada a partir da solidariedade que leva Kriss hoje a ter dois hostels, sendo um para marinheiros da $\mathrm{Ma}-$ rinha Mercante em trânsito e pacientes em cuidado indicado pelo Serviço de Atendimento da Capitania dos Portos do Rio de Janeiro (CPRJ). Kriss contou sua trajetória para os estudantes de arte que imediatamente ficaram interessados em colaborar em diversas proposições descritas, tais como o Salão de Beleza para as moradoras de rua, acolhimentos e visitas ao CPRJ nos fins de semana, entre outras atividades sociais.

O primeiro impacto ao entrar no Bar Delas foi sua riqueza ética-estética. Uma aura era captada pelos estudantes de arte, pois ali pulsava um sentido vital até então desconhecido, de vidas solidárias (da ocupação) como arte, para além da arte, à margem do individualismo da correria urbana. Imaginase o quanto Thelma, vindo de São Paulo, não teria encontrado ali o chão para sua cambalhota existencial, para inaugurar e inventar futuros compartilhados de construção coletiva. Porém, a partir do encontro 
com a Thelma, a vida da Kriss também tomou um novo impulso. Observando a vizinhança do Bar Delas, na esquina das ruas Pedro Ernesto e Sacadura Cabral, têm-se em diagonal oposta a Praça da Harmonia, o seu coreto isolado no tempo, e o antigo Moinho Fluminense, uma imensa construção de tijolos aparentes, que são demarcadores do palimpsesto e anacronismos que envolvem as invasões contemporâneas da gentrificação da Zona Portuária.

Certamente poderiam ser lembradas várias experiências e tentativas utópicas de artistas de fazerem restaurantes, tais como a proposta anarquista do Food in Soho, cofundado por Gordon Matta Clark em 1971. Ou mais recente, de Asia Komarova ${ }^{6}$ em sua residência no Capacete que se desdobrou em sua experiência atual na Holanda como espaço de convivências e de comunidade de saberes - no qual coloca em questão os desafios de elaborar um desenho comunitário e dos engajamentos coletivos. Os debates e tendências para a busca por experiências comunitárias estão presentes como utopias pragmáticas desde as rupturas dos anos 1960, conforme já abordadas no texto de Hélio Oiticica - os sentidos apontando para novas transformações. Dos barracões aos espaços públicos e às células de cocriação e compartilhamento de outros saberes, de Oiticica às tendências e posicionamentos decoloniais de hoje, as táticas de resistência e de resiliência da arte são conduzidas pelas desobediências epistêmicas e distopias do contemporâneo. Kriss faz parte desta distopia sem preocupações em ser ou não ser arte, mas certamente o Bar Delas é uma escultura social, um campo imantado que abriu um horizonte de reinaugurações para a própria Thelma a partir do fim de sua residência artística no espaço Saracura em 2018. Com os casos de entrelaçamentos entre vida e ações solidárias da Kriss, Thelma e Ligia é possível parafrasear Krenak - para reunir visões e "ideias para adiar o fim do mundo, também da arte e de um bairro chamado Gamboa.

\section{Kriss Coiffeur - KC}

1. Sou Kriss, Christiane Rodrigues, mas as pessoas me chamam de Kriss, tenho 43 anos, moro no bairro desde quando tinha um ano de idade. Nasci na Bahia, e meus pais, sendo caminhoneiros, viviam indo e voltando entre Rio e Bahia. Moro aqui no

Luiz Guilherme Vergara, Kriss Coiffeur, Ligia Veiga, Thelma Vilas Boas. Escola do mundo: ideias para adiar... 
Bairro da Saúde desde um ano, mais ou menos. Isso aqui é super lindo.

2. Vou falar um pouco mais da Thelma. Quando a Thelma apareceu aqui foi muito lindo. Quando ela chegou perguntando quem era a dona (janeiro de 2018). E era eu, uma mulher, e não tem dono, sim dona. Thelma é como se fosse minha alma gêmea. Quando eu vi muita gente bonita passando pelo bairro, indo e voltando, pensei que bem que esse povo poderia parar aqui no bar.

3. O Bar Delas não é um bar de bêbados. Não é um bar que tem briga, não é só um bar. O Bar Delas é tua casa, é acolhimento, todas as pessoas que chegam comem, ficam, o morador de rua pede para tomar banho. Crianças vêm comer, jogam flipper, sentam ali, dormem. - Tia "qual é a senha? qual é a senha?"

É um lugar que eu e a Thelma tiramos as crianças da rua. As crianças do bairro ficam até 2 e 3 da madrugada na rua. Os pais não querem nem saber.

4. A preocupação do afeto. Eu e a Thelma nos separamos e não nos separamos. A
Thelma está na parte de lá na escolinha, no dia a dia - e aqui o Bar Delas.

Eu e Thelma queremos fazer um salão de beleza, dar aula de graça para adolescentes de barbeiro. Vamos dar um curso e depois dar trabalho. Não queremos perdê-las para o tráfico. As crianças e adolescente de 12, 13, 14 e 15 anos - daqui a pouco nós as perdemos para o tráfico... elas vão querer um chinelo... e não tem dinheiro. E então perdemos para o tráfico.

Eu e Thelma tínhamos pensado em fazer um curso profissionalizante. A Thelma faz a escolinha para os menores e, aqui, faremos um curso de barbearia para crianças a partir de 12 anos, para não as perder para o tráfico. Aqui terá curso gratuito para formação em barbeiro. Aqui já é salão, é lavanderia. Aqui todo mundo almoça, todo mundo fica. A revitalização [gentrificação] do bairro fez que eu acordasse para esse lado. De juntar com Thelma e pensar em algo diferente para os adolescentes para as crianças do bairro. E estamos aí. Estamos aí lutando para isso. Vamos abrir uma chamada agora em novembro. 


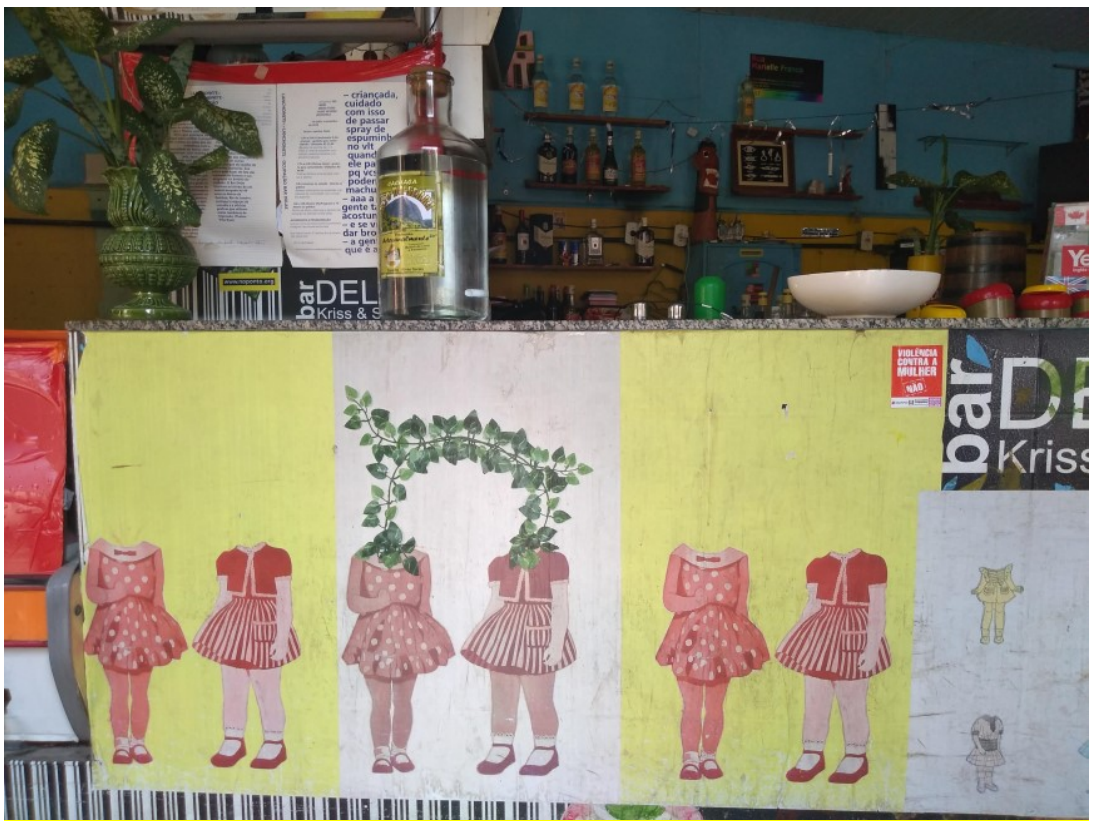

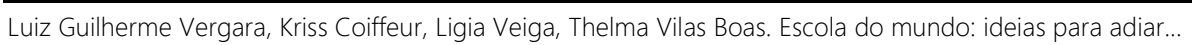



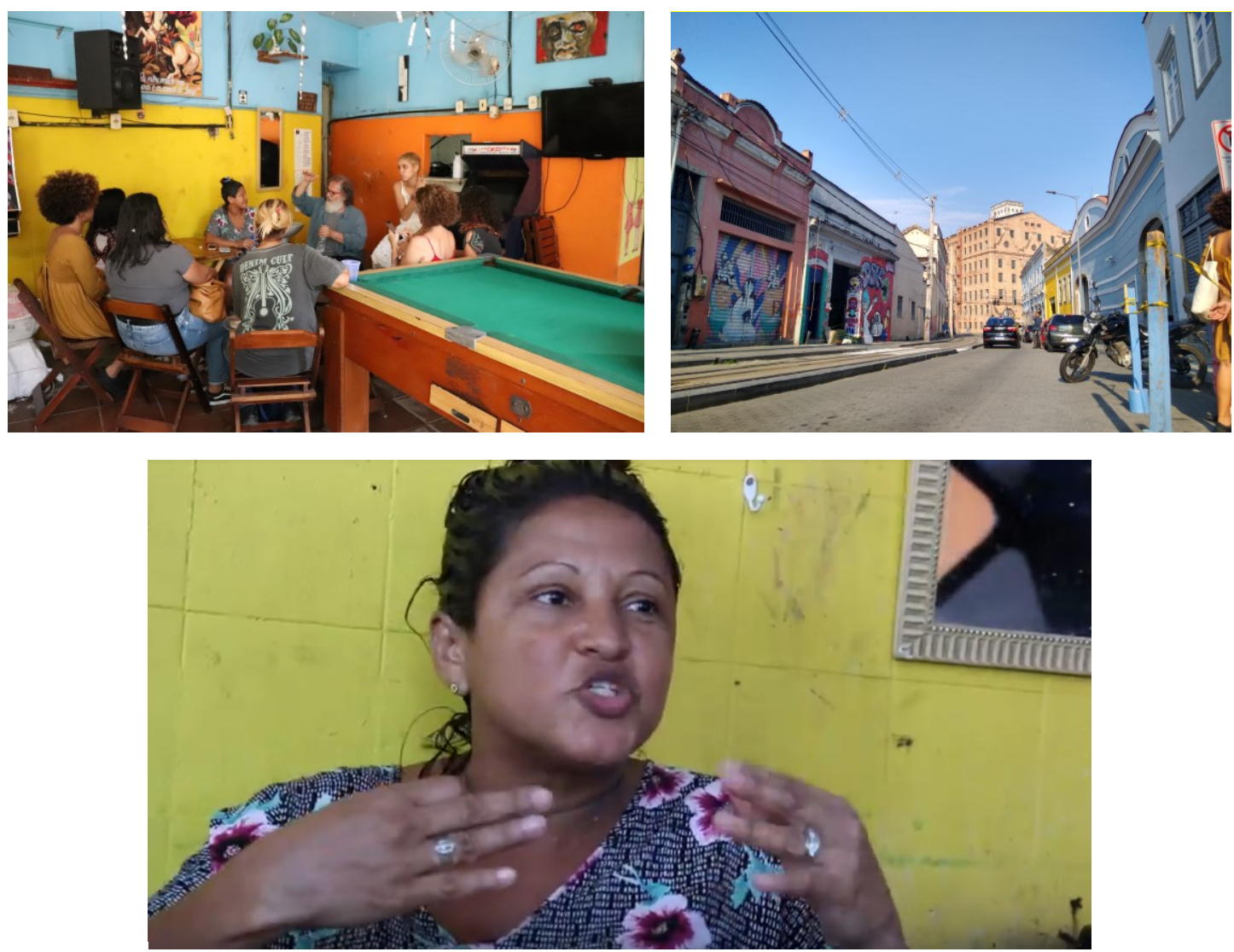
5. Se me perguntar do que eu gostei na mudança do bairro - gostei só de ter gente nova. Mas não gostei de muitas coisas que aconteceram no bairro com essa revitalização, tipo tirar os ônibus, tirar os empregos de muitos moradores do bairro. Porque o Moinho Fluminense (está fechado) ... segundo algumas pessoas, vai ser shopping, vai ser prédio residencial; vai ser um Copacabana Palace, um Copacabana de 6 estrelas. Tudo que está acontecendo no bairro hoje não é para nós, não é para morador do bairro. Com essa revitalização acho que umas 2000 pessoas foram embora do bairro.

6. Aqui somos uma ocupação de 40 anos... e agora apareceram uns donos "picas" (já gastei $16 \mathrm{mil}$ reais de advogado) brigando por espaço. 0 dono que não aparecia há 40 anos, você imagina, agora apareceram 5 donos - todos 5 advogados. O juiz vai dar causa ganha para quem? para os donos? Não quero ter advogado... eu não preciso de advogado porque vou ter que mentir, eu não quero mentir.

7. Ano que vem vou fazer faculdade - vou fazer ciência social - que maravilha viu; depois de 40 anos vou decidir o que quero e queria fazer. Eu nunca quis fazer faculda- de - sempre trabalhei para mim, desde 12 anos. A minha mãe sempre teve bar, por isso sou apaixonada por bar.

Trabalhei 10 anos na faculdade, na Gama Filho aqui na Candelária. E nunca quis fazer faculdade porque todo mundo que faz faculdade continua trabalhando na Gama FiIho, na mesma profissão, nunca exerceram a profissão que fizeram na faculdade. Eu nunca quis fazer faculdade, eu tinha bolsa integral e tinha meu marido, eu tinha (bolsa da marinha), nunca quis fazer faculdade. Depois disso tudo, depois da Thelma (olha só que descoberta), quero fazer faculdade sempre gostei de trabalhar para mim, ter bar, tinha outro bar perto da colina.

8. Depois dessa mudança todinha foram tirados 2000 moradores. O homem daqui não está conseguindo dormir. Você imagina, por que aqui é uma residência onde moram 10 famílias... aqui tem a gráfica, 25 pessoas trabalham, tipo tudo vai acabar. Aqui tem duas residências que fazem parte do coletivo.

9. Eu acho que queria meu bairro de volta, porque quando não tinha isso (revitalização) era tudo bem natural. Muitas famílias foram embora com esse sonho da minha 
casa e minha vida, isso é ridículo, é uma farsa. Você fica submisso ao tráfico ou aos milicianos. Eles começaram a tirar as pessoas, [prometendo] que vai te dar uma casa. Tem pessoas que não pagam nada... ou pagam $R \$ 27$ a $R \$ 42 \ldots$ as pessoas ficaram na empolgação de ir embora, de entregar o imóvel daqui porque iam ser cadastradas para receber uma outra casa. Foi todo mundo embora. O Eduardo Paes veio, começou a oferecer casas. Falei com o Eduardo Paes, na rua oferecendo casas, fazendo cadastro.

Todos que ficaram [no bairro] estão submissos ao tráfico. Onde a boca de fumo hoje é aqui, amanhã é ali. Meninas de 12, 13 e 14 anos engravidam. Porque você cria as suas filhas bonitinhas para o tráfico. Os bandidos não respeitam mais ninguém. Todas as favelas são assim. Sua filha começou a ficar bonitinha, eles querem "namorar", antigamente não tinha isso.

10. Olha só o que essa revitalização fez... muitas pessoas perderam suas vidas, perderam seu sossego... perderam tudo. E no final, eu creio que daqui a pouco, os outros $80 \%$ ou $70 \%$ que ficaram vão também embora. As coisas estão ficando caro, os aluguéis e o IPTU.
11. O mercado vai sair daqui. Dizem que vai vir um maior, mas ninguém sabe quando. Segundo alguns moradores dizem, [0 dono do mercado] investiu em um hotel ali na Rua Camerino. E ainda, com essa roubaIheira todinha, os japoneses desistiram. 0 dono desistiu... está fechando o supermercado... Aí ferrou, se fechar, se não tiver mais mercado, a gente daqui vai comprar onde??? Se fechar, não vamos ter o Mundial (supermercado) do Santo Cristo.

12. O comércio realmente caiu muito, a gente não sabe como esse povo está sobrevivendo. Tinham 10 mil trabalhadores (funcionários) no Moinho Fluminense, 90\% morava aqui, também tinha uma fábrica de panela, sindicato da Marinha Mercante, o cais, a estiva que dava emprego para 5000 funcionários que vinham aqui beber... ter um bar onde essas pessoas vinham e podiam beber ter um bar aqui era ser rico. As pessoas têm esperança no Moinho, mas começo a pensar que se tiver um shopping aqui, será que eles não vão parar de beber uma cerveja aqui no bar? Porém, com os restaurantes Girafa, Pilão de Pedra ou um Habib's, o shopping vindo para cá vai acabar com o comércio... a não ser depois das $22 \mathrm{~h}$... você vai ter o "resto" vindo para cá beber. 


\section{Ligia Veiga - Companhia de Mysterios e Novidades / Escola sem Paredes}

Ao entrar na casa que abriga o universo da Grande Companhia de Mysterios e Novidades têm-se um confronto imediato com um imaginário de Borges - fora do tempo, transtemporal. Palimpsestos e anacronismos eclodem como tempo cíclico - Kairós que é também uma visão concreta de uma escola de arte e devir floresta. Como Ligia Veiga vem atravessando estes tempos sombrios e se mantendo resistente como lugar - guardiã de futuros e utopias de várias gerações?

Um grande quadro-negro chama nossa atenção por tantas palavras de resistência: CORAGEM - que logo é complementada pela própria Ligia como Agir do Coração. Logo ao lado $1 / \infty$ que acompanha a Ligia como presença e homenagem a Guilherme Vaz.

Ali se inscrevem: Coletivo Cósmico. Nós somos o sonho de nossos ancestrais... Lugar escondido de todos os tempos...

\section{Genealogia de uma Escola sem Parede}

1. Aqui é um lugar que está cheio de camadas. Trabalho sobre estas afinidades, expressões artísticas que a gente busca. $O$ trabalho da gente é um trabalho de arte pública. Essa sede é um lugar onde criamos nossos espetáculos e pesquisa. Aqui se estuda e se encontra. E vai abrindo janelas e portas... A nossa potência maior é a rua... ir para a rua fazer as coisas. Onde a gente se sente mais vivo e livre.

\section{Comecemos pelo Grupo Coringa. O Gripo} Coringa era uma companhia de dança, um grupo que se juntou a partir de Graciela Figueroa, uma mulher fantástica, uma mulher luminosa, dançarina fantástica com a capacidade de juntar pessoas. O Grupo era completamente anarquista fundado entre 1977, quando as coisas estavam começando a fluir a partir da Escola de Artes Visuais do Parque Lage, sob a direção de Rubens Gerchman. Hélio Eichbauer se juntou à Graciela Figueroa. Ambos foram importantíssimos na dança contemporânea no Rio, provocando e motivando muitas situações (experimentais). Eu tinha 17 anos, detestava dança naquela época. A gente só via dança clássica. Quando vi essa mulher dançando

Luiz Guilherme Vergara, Kriss Coiffeur, Ligia Veiga, Thelma Vilas Boas. Escola do mundo: ideias para adiar... 
no MAM, fiquei louca. É isso que quero fazer. Ela era como uma égua dançando, uma jogadora de basquete misturada com uma gazela pulando saltando.

Imediatamente a coisa aconteceu. Trabalhando com esse grupo, aquela coreógrafa bailarina louca criou o Coringa (1977-1985), provocando uma ação muito forte entre todos nós de criação e dança. Além dessa mulher e também do que estava acontecendo na época da EAV com direção do Gerchman, Hélio Eichbauer foi outro protagonista deste momento. Ele era um mago. Botou muita gente, gente de todas as idades, pessoas mais veIhas que conheço até hoje, para se envolverem de tal maneira com aquela oficina pluridimensional fazendo performances e espetáculos. Eu trabalhava durante a semana, estudava e ia fazer as coisas, desde espetáculos sobre Isadora Duncan (1877-1927), Gordon Craig (1872-1966), Bauhaus. Vanguarda Russa... Shakespeare... música brasileira - tudo misturado.

3. Era uma universidade sem paredes. Ia aprendendo as coisas na medida que ia fazendo as coisas, experimentando as coisas. Uma coisa muito linda, uma maneira de aprender, experimentar e viver as coisas muito única.
4. A minha formação passa um pouco por tudo isso - sou uma pessoa autodidata. Nunca fui para universidade. Mas tive mestres incríveis. Isso aqui (a Grande Companhia de Mysterios e Novidades) é um pouco o resultado dessa mistura, desse amalgamento de experiências de grupo, experiências coletivas mesmo. Eram potentes experiências coletivas com pessoas variadas, muito diferentes. Isso era uma coisa muito incrível nesses anos, nessa época - tinha essa questão da diversidade. Não existia nenhum preconceito com relação ao preto, branco, amarelo, gay, apesar de estar ainda na ditadura. Naquele oásis do Parque Lage que juntou Graciela Figueroa e Hélio Eichbauer, a gente vivia lá, atravessava a madrugada, dormíamos lá, fazíamos coisas na piscina... o Uirapuru, várias montagens, incluindo o povo da poesia... Chacal. $\mathrm{Na}$ época eu era muito jovem, não percebia a ditadura naquela época, não tinha noção... aquilo ali era uma bolha. Eu não percebia a ditadura... era um oásis.

5. Eles não percebiam a ameaça que era Arte; não se percebia que era ameaçadora. 


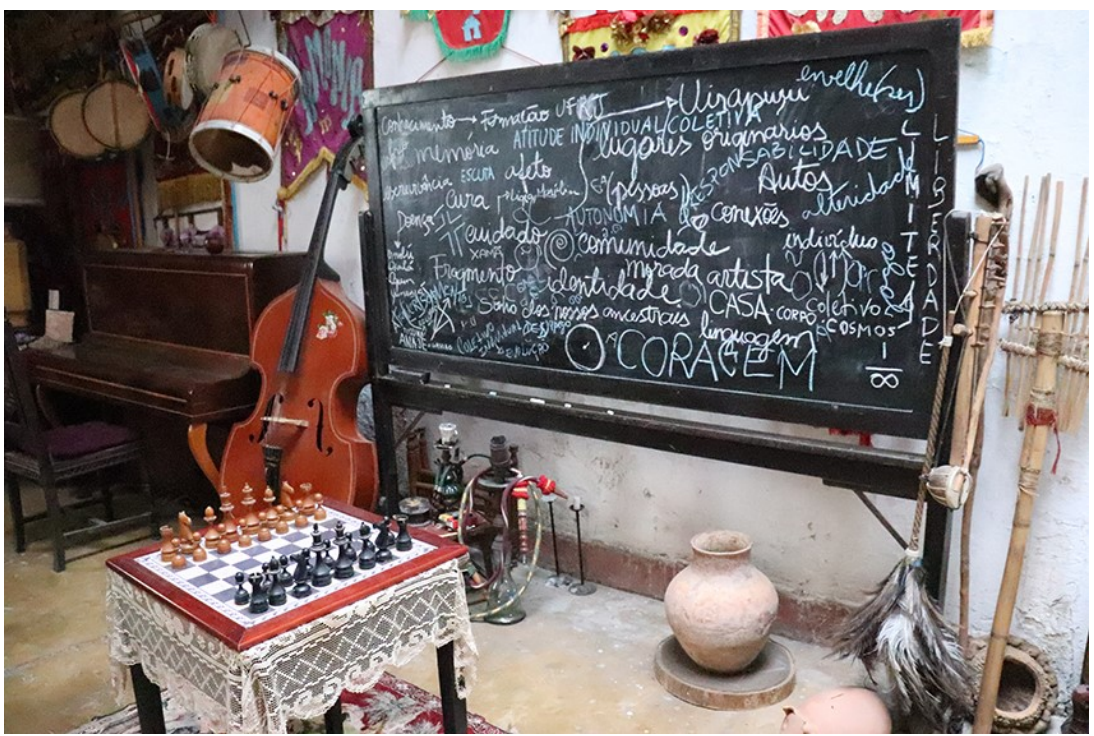

Luiz Guilherme Vergara, Kriss Coiffeur, Ligia Veiga, Thelma Vilas Boas. Escola do mundo: ideias para adiar... 

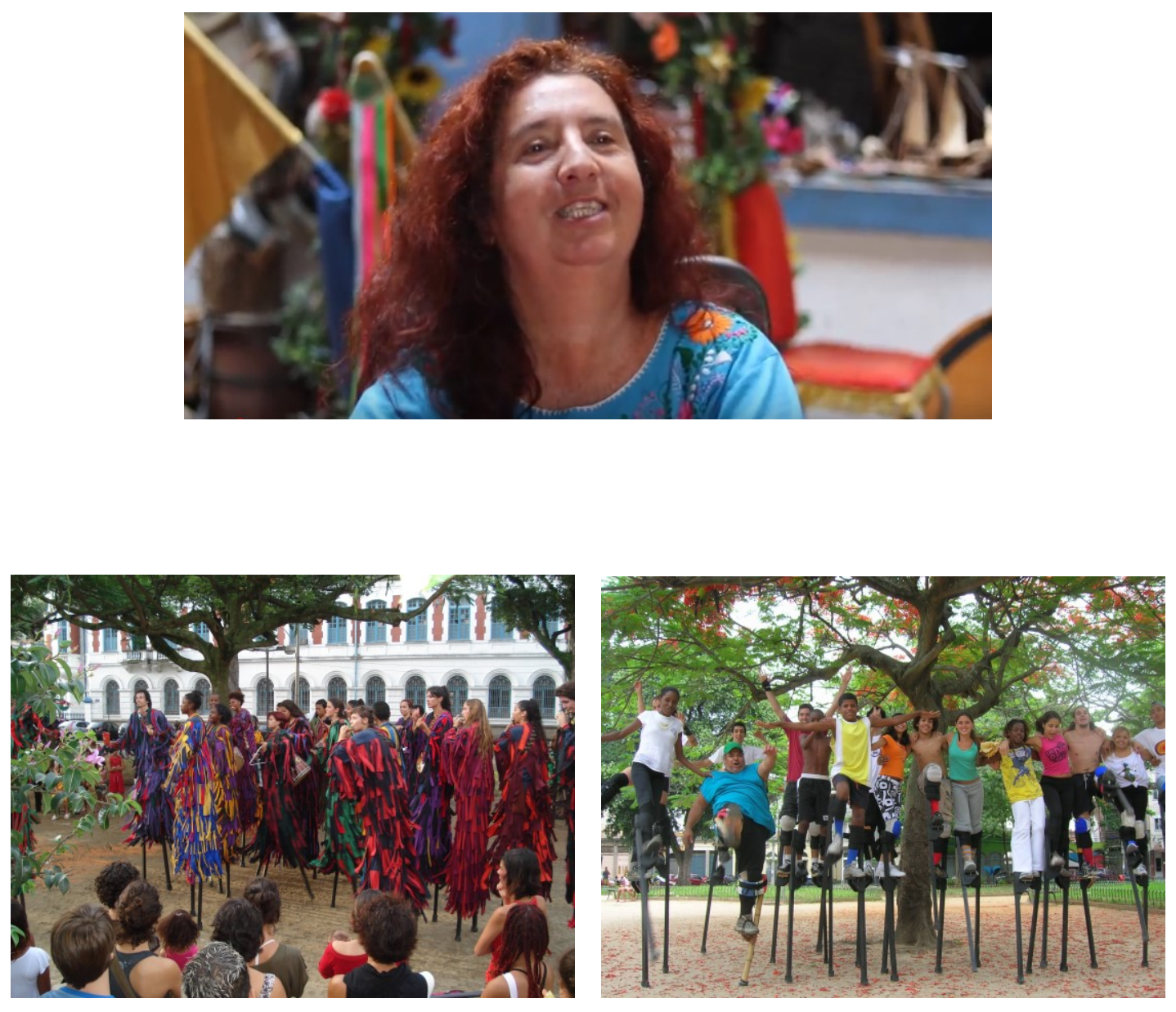
Dos cortejos às Procissões de Todos os Santos - uma escola de arte para a rua / arte pública

6. A história dos cortejos deu origem as Procissões de Todos os Santos desde o Largo de São Francisco, que hoje já completam 20 anos. A Grande Companhia de Mysterios e Novidades nasceu em São Paulo. Fiquei morando em São Paulo nos anos 90. Quando eu vim para o Rio em 2000, eu queria voltar para o Rio. Eu achava que o Rio era uma cidade potencialmente de rua... Sentia que em São Paulo era tudo cercadinho. O SESC comprava as ações.

O Rio é uma cidade potencialmente de rua. Quis voltar para o Rio e fazer o trabalho aqui. Quando voltei, encontramos um lugar no Largo das Artes na Rua Luis de Camões, fizemos obras, tiramos paredes.

7. Eu e a Lia Rodrigues nos encontramos em SP - em uma itinerância de nossos trabalhos no projeto "Saravá Mario de Andrade" que ela idealizou e acabou vendendo para o SESC e aí nos tornamos muito amigas. Propus vir para o Rio - "vamos conseguir um espaço". Encontramos um lugar no Largo das Artes na Rua Luis de Camões, 2.
Fizemos obras, tiramos paredes. Antes, Antes, tentamos a região portuária. Nessa época, isto aqui estava completamente abandonado. Aqui (a Zona Portuária) era um lugar dos excluídos. Essa coisa toda do Porto Maravilha que deu uma embalagem para o porto - não para dentro. O olhar é ainda de fachada e da borda...

8. Tirou os ônibus daqui - e colocou o VLT. Esse lugar aqui era dos excluídos...

9. O Largo das Artes estava fechado há 5 anos (em 2000) e o Miguel Saad queria fazer alguma coisa. Propusemos ao Miguel de restaurar o prédio para não pagar aluguel. Arrumamos o espaço. Ali, a Lia Rodrigues fez "Daquilo que somos feitos" e eu fiz "o Tal do Mundo".

10. A partir do Largo das Artes começamos a atuar na praça (Tiradentes e o Largo de São Francisco). Durante 7 anos (20002007) fizemos (a Grande Companhia de Mysterios e Novidades), com os moradores de rua, apresentações na praça. E aí começamos a fazer um cortejo - que juntasse os orixás, entidades, santos, criando uma legião de ano em ano, que atravessava do Largo de São Francisco à Praça XV, que entrou no calendário da cidade - todo 10 de no-

Luiz Guilherme Vergara, Kriss Coiffeur, Ligia Veiga, Thelma Vilas Boas. Escola do mundo: ideias para adiar... 
vembro. Agora fazemos da Praça Mauá até aqui na Praça da Harmonia... esse ano vai ser a vigésima (2019).

11. Hoje temos um calendário de atividades na praça: 23 de abril - Cortejo de São Jorge, que sai da Praça Mauá... desde 1994. Esse ano fizemos o cortejo de São Jorge - A Saga de Jorge; é o começo do calendário da gente da praça.

\section{A história da compra da casa na Gamboa e São João}

12. Uma história especial da compra da casa na Gamboa e São João: temos a Festa de São João - festa junina - como muito importante em nosso calendário e história. Essa história é muito boa.

13. Ganhamos o patrocínio da Oi Futuro para produzir o projeto "Gigante pela própria natureza", projeto que tentamos manter a duras penas. Este programa de oficinas gratuitas tinha como objetivo desenvolver um trabalho de teatro de rua, participando com a Companhia Mysterios e Novidades. Ganhamos esse patrocínio - mas, ao mesmo tempo, estávamos sem espaço.
14. Aconteceu uma coisa muito incrível. Saindo da Luis de Camões, depois de 7 anos lá, mas já no olho da rua, eu voltei a procurar aqui na Zona Portuária (2007), não tinha onde ir - botamos as coisas no antigo Cais do Pão - na Rua Sacadura Cabral. Botamos as coisas lá e fomos procurar um galpão, até encontrar essa casa e Dona Marlene.

15. Essa casa (originalmente) foi comprada por um imigrante português, sapateiro, sem dinheiro, que comprou um bilhete de São João e ganhou. Na casa do outro lado, ainda tem o São João com uma luzinha mantida dos antigos proprietários.

16. Passamos por aqui e esse lugar estava à venda. Dona Marlene morava ao lado, onde moro agora. Quando conheci a Dona Marlene, ela já estava em negociações com um carnavalesco que ia comprar esse lugar. Mas, depois desse encontro - ela cancelou a venda, e esperou 6 meses para conseguirmos o dinheiro para comprar a casa. Conseguimos empréstimo... Não tínhamos dinheiro para nada. Conseguimos começar o projeto com a nossa madrinha (Dona Marlene).

17. Dona Marlene, a filha do proprietário, contava que vinham bater à porta querendo 
comprar esta casa. Ele falava que não, seu pai não queria vender, preferia que a casa continuasse assim. Para o pai dela a casa era muito importante, preferia não vender não ter dinheiro -, mas continuar morando com os filhos ali. Ele era um cara muito resistente.

18. Nós (Companhia de Mysterios) nunca tínhamos comprado uma casa na vida. E a Dona Marlene, que já era uma senhora, também nunca tinha vendido uma casa. Dona Marlene foi ao cartório - a companhia toda foi junto com os filhos e netos... todos juntos emocionadíssimos - a gente, porque ia comprar a casa, e ela, por vender. "Eu sei que vocês são resistentes que nem meu pai"... foi uma coisa muito importante. Ela deu um chaveirinho com São Jorge. "Eu sei que vocês são resistentes que nem meu pai. Espero que nunca precisem vender a casa."

19. Esse lugar foi construído aos poucos. Não tinha esse galpão. Agente derrubou um galpãozinho, depois fez as fundações, o chão e só então fizemos o novo galpão. Todas essas etapas foram celebradas.

20. Se o Porto Maravilha tivesse dado certo muitas das ocupações já teriam sido deslo- cadas. O Moinho Fluminense já estaria sendo adotado como shopping. As torres não deram certo.

21. Temos (até hoje) a Festa de São João festa junina - como muito importante em nosso calendário e histó-ria. Essa história é muito boa.

22. Continuamos desenvolvendo os projetos da Procissão de Todos os Santos, um evento artístico aberto; todos que queiram participar, nas pernas de pau ou no chão, são convidados a vestir seus santos, saindo da Praça Mauá até a Praça da Harmonia. Assim também a Companhia participa do Festival Gamboa de Portos Abertos - Literatura, colaborando com a comunidade. 


\section{Thelma Vilas Boas - Escola Por Vir / Lan- chonete <> Lanchonete}

1. Estava ouvindo você falar dessa história toda e estava aqui lembrando dos ensinadores dos Huni Kuin, que eu perguntei há quanto tempo eles tinham começado a transcrever aquilo que eles comunicam em oralidade. Parece que é uma coisa de oito, quinze anos... Quando eles me disseram isso, que eles trouxeram inclusive as cartiIhas que eles desenvolvem com os estudantes indígenas... Foi curioso porque lendo $A$ queda do céu, o Davi Kopenawa fala "pobre dos brancos que precisam da folha de papel", se referindo ao papel, como a pele de papel, "para guardar o mundo. A gente conta e reconta aquilo que nossos avós e nossos tataravós sempre contaram... Nossos Pajés, nossos Caciques, então a gente não precisa da pele de papel". Então, para mim, me pareceu interessante perguntar... Por que ele estava muito orgulhoso de contar que há uma década, pelo menos, eles começaram a alfabetizar a comunidade, as crianças? Elas fazem a rotina de ajudar a família de manhã em casa. As meninas na roça com a mãe, os meninos em um fazer com os pais. E que à tarde eles vão para a escola para esse letramento. Aí dentro des- sa minha curiosidade e surpresa, ele responde que toda vez que um Pajé morre, morre uma enciclopédia de mundo. É como se queimasse uma grande enciclopédia histórica, quase que milenar. Então ele se sentia muito feliz de ver que isso estava sendo conservado em livro.

2. Eu te conto essa estória porque quando ele me fala isso, me faz pensar justamente sobre a profissão acadêmica, que quando me garante essa produção e esse saber vivido por milhares de anos, e por uma Floresta, me parece contundente e muito importante que isso esteja registrado. Mas na produção acadêmica, me parece que a gente escreve sobre mortos, e não sobre práticas e experiências vividas. A gente vai fazer citações, a gente escreve dissertações e teses em cima de autores mortos, citações europeias, autores europeus, referências bibliográficas europeias... Ou coisas que a gente nem experimentou viver, mas lê e escreve. Cita e legitima.

3. Então o que eu fiz dentro desse caminho tão acadêmico foi justamente poder viver uma prática para que em retrospectiva pudesse se edificar alguma teoria. Sem dispensar o respeito a toda essa produção de 
inteligência, que nos traz aqui hoje. Mas dando um espaço para que quando alguma coisa for de fato registrada, que ela seja registrada porque ela é nova, porque ela é contundente, porque ela realmente é importante.

4. A Escola Por Vir, o nome que me ocorreu, justamente porque eu acho que nesses tempos todos, depois de alguns anos, eu fiquei oito anos dentro dessa experiência. Primeiro eu cozinhei na rua, depois teve a experiência da residência artística, depois como Lanchonete no Saracura, depois um ano na Cris, agora esse ano aqui, é justamente a ideia de me forçar a me arriscar mesmo, a pensar o que está "por vir", antecipar um tempo, para que a gente possa dar respostas ao imponderável. Que é justamente isso o que a gente tá encarando.

5. Agora... Me parece que isso é tão grande, tão grande que tira o fôlego, sabe? É muito mais da ordem do sensível que da lógica, como se meu corpo inteiro pudesse perceber e se sentir comprometido com demandas que são do coletivo, onde me faz pensar muito mais que o limite de unidade e conjunto é só a minha pele, nada mais que minha pele que separa o fora e dentro e tudo é conjunto... Que para dentro eu sou conjunto e para fora eu sou conjunto... Qual é essa ideia de unidade? Onde foi que surgiu essa ideia de unidade? Não existe muito isso, sabe? E como que a gente foi deixando de atomizar esses conceitos de coletivo, por um projeto de poder, um projeto capitalista que se instaura nessa civilização moderna, que nos fez mais ignorantes... Tanto é que a gente está levando a lavada que estamos levando agora. Que são justamente os povos originários e as minorias que estão apresentando possibilidades de mundos possíveis.

6. Não é sobre um futuro possível, é como a gente pode agora desafiar os dilemas e os paradigmas... A gente está bebendo na fonte das minorias, dos povos originários, dos aldeamentos, dos quilombos... Não está vindo essa resposta da ciência branca acadêmica letrada, descolada da vida, sentada em um lugar de um saber que separa o homem do outro, o homem da natureza, o homem dos problemas...

7. Então inventar uma escola é também tentar responder ao que se dá com a maior potência de ser, a maior potência de criar... Não daria para ser cópia, porque a gente 
sabe que qualquer projeto precisa ser readaptado ao seu contexto, ao seu lugar, ao clima, ao bairro, à rua, à economia, à língua, ao grupo de pessoas, aos gêneros participantes, todas as coisas... Então como que poderia surgir uma escola que não fosse por vir? Seria desonesto da minha parte, propor uma coisa pronta, porque é impossível você ter um projeto pronto. Então, é acreditando mesmo neste processo orgânico, sincero, difícil pra caramba, sabe?

8. Hoje recordei um pouco aqui com as meninas e falar sobre o que aconteceu hoje, que a gente tinha vinte crianças aqui... Como isso me toca, sabe? No sentido de não querer ser de novo uma colonizadora... Que quando eu oriento os gestos de uma criança, os modos de uma criança, o quanto nisso também não estou domesticando uma criança? E eu não quero passar por esse papel. E o tempo inteiro eu estou visitando esse lugar e me perguntando, me fazendo perguntas severas comigo, me cobrando mesmo exatamente todos esses gestos.

9. Porque onde a gente chega aqui, na Lanchonete, só para dar um pouco assim da paisagem, a gente chega em uma terra desertificada, a gente chega em uma terra com fome, com medo, com corpos respondendo em uma vibração molecular super agitada, e que não teve uma domesticação em casa tal qual eu, enquanto classe média de uma família rural, operária, São Paulo, periferia, teve o que se poderia dizer a norma média de modos e comportamento. Como a gente recebe uma criança dessa, que não só é a criança perfil desse lugar, mas a maioria do Brasil?

10. É evidente que o Brasil está gestando uma população, não sei qual percentual dentro desses duzentos milhões de habitantes, uma população muito carente em sua constituição de subjetividade.

Eu não posso dizer as qualidades ou as faltas, porque isso seria violento da minha parte, mas óbvio que essas pessoas e essas subjetividades estão sendo construídas sob a sombra do horror, do medo, do apagamento histórico, do lugar de fala que não tiveram, do preconceito, do racismo... Aí fico pensando como eu, uma mulher branca, que aposto em um território porque venho de uma pesquisa acadêmica e que leva um "tapa na cara", quando percebo que minha produção artística me constrangia, como você fala... Como pensar produção artística 
em dois mil e pouco? Eu comecei isso em 2011, mais ou menos, resolvi vir para perto da Baia de Guanabara para poder entender essa desgraça, essa diferença social, esse mal-estar civilizatório, e percebo que não podia ser uma pesquisa acadêmica. Era uma grande reviravolta na minha constituição biográfica. Como eu iria realmente me sentir afetada por isso?

11. Curiosamente, não foi na intelectualidade que eu me senti confortável, foi na cozinha. Foi a cozinha que me fez lembrar um certo conforto e uma certa confiança que eu tinha da minha vida na roça. Aquela cozinha que minha mãe cozinhava, minha avó bordava, abria porta entrava galinha, sabia matar porco, cuidava das plantas, fazia remédio... E toda a geração com que eu cresci dizia para mim, "saia do campo, vá para cidade", vira uma pessoa da cidade. Estuda em uma faculdade, se constitui um ser independente, entra no sonho da casa própria, trabalha e financia sua casa. Então são várias chaves que foram sendo desativadas para ativar uma outra que aumentou minha humanidade. Ou melhor, acho que foi a primeira vez depois que cheguei na cidade, saí do interior que eu consegui falar "Uau!! Existe uma humanidade em mim".
12. De início, a Lanchonete era uma cozinha. Antes foi na rua, depois foi uma cozinha, aí foi muito óbvio para mim me lembrar do quanto a fogueira, o estômago e o fogão cumpriam a mesma função de dividir em partículas aquilo que a gente não pode ingerir por inteiro. Por isso que a gente fica horas em volta da fogueira. Porque a gente está engolindo coisas cósmicas, coisas de outras linguagens, a linguagem do sensível. O estômago faz isso, o fogão faz isso. Por isso que eu insisto muito em começar pela cozinha, porque eu acho que é o grande laboratório da casa. A sala de jantar é onde estão "as pessoas da sala de jantar". Aí comecei a entender que minha produção enquanto artista, se existe um objeto, é tecido social. Se existe um formalismo, é tecido social. A gente só não precisa colocar em uma galeria, não precisa colocar dentro de uma sala, a praia... Se a gente já vive isso, porque a gente precisa estetizar a esse ponto para nos tornarmos sensíveis aos problemas do outro?

13. Acho que é hora realmente de a gente acreditar nessa micropolítica, nesses microgestos. Tem uma outra coisa que me toca muito, que é um livro: Há mundo por vir?, do Viveiros de Castro e da Deborah Dano- 
wski, que eles falam uma coisa: "o mundo acabou". E acabou mesmo. A gente, eu acho, que ainda não acabou, porque a gente está vivendo, mas "o mundo" já acabou. O mundo está indo em direção ao seu fim. Quando eu o vejo falar isso me causa uma tremenda angústia, mas daí ele fala: "vive o luto". Eu acho que é isso, sabe? As pessoas estão ainda tomando calmante... "Não! Vive o luto!". Faz que nem o filme do Lars Von Trier, Melancholia, que ela faz uma cabana de graveto.

14. A Lanchonete, acho que é uma cabana de graveto. É a cabana de gravetos que eu posso oferecer. Tem milhões de falhas, quem vem aqui no dia a dia percebe que está cheia de lacunas... Mas é uma cabana de gravetos, está aí com a porta aberta, estou pagando as contas, estou chamando "Habitem!"

15. Mas voltando para o que ele fala, "vive o luto". Acho que quando a gente vive o luto, a gente sai dessa chave de hipocrisia, desse lugar de que "está tudo bem, segue aí, vamos andar de lancha." O lado bom de viver o luto: pare de ser megalomaníaco, não é mais hora das megainstitucionalidades, é hora de pequenas institucionalida- des. Pequenas políticas. É assim que a floresta funciona. São pequenas aglomerações se organizando e se organizando de novo. O nosso único sinal de que a gente pode ser uma unidade é a pele. Para dentro e para fora, a gente é conjunto.

16. Eu, como uma mulher branca, com uma experiência de asfalto, de classe média operária, ABC Paulista, o que eu posso me lembrar é que, se eu fosse negra, se eu fosse indígena, eu também saberia que a floresta está indo embora. Por isso escolhi elogiar a floresta, por isso que na porta tem uma floresta. Plantas que eu já cultivava em casa eu trouxe, tentando que, aos poucos, cada criança se vincule com a planta. Para que cuidando dessa planta, ela possa cuidar dela mesma, que cuidando dessa planta, ela possa cuidar do planeta.

17. Uma coisa linda que ouvi da Sônia Guajajara; que "a gente não vai ter medo de morrer para defender nossa floresta". Eu não tenho coragem de enfrentar para proteger a minha cidade, do jeito que ela diz. Outra coisa que ela disse é que, antigamente, em duas horas eles entravam no rio e pescavam o peixe para comer, agora eles ficam dois dias para pegar o peixe. Ela não 
reclamava ali somente do rio que deixava de ser rico em alimento, mas, também, "como assim ficar dois dias trabalhando, com tantas outras coisas maravilhosas para se fazer na floresta?" Então eu achei que uma coisa que eu poderia contribuir aqui, que seria meu lugar de fala, aqui na Pequena África, na Gamboa, era fazer um elogio desse jeito, com essa Escola Por Vir.

18. Cada criança adota uma planta, dizemos que as plantas podem falar com elas, que elas vão responder de um outro jeito, que elas se mexem, e insistir em um paralelo de que toda semente guarda uma promessa. Uma promessa de futuro, não é? Um Baobá dá 500 anos de futuro.

19. Uma criança é uma semente que guarda a promessa de um futuro. E que futuro é esse que eu, como artista, não vou me importar? Vou cuidar da plantinha em casa? Vou ter um vasinho na sala? Qual é essa semente mais próxima da minha humanidade? A semente humana, não é? Não só aquelas que eu pari, mas aquelas que estão no mundo.

20. Aí as crianças cuidam das plantas. A gente tenta ter sementes quase todo dia, eu trago umas sementes diferentes, algumas dessas que tem "barbatana" que voam para tentar fazer associações. Comem comida não processada, porque toda criança preta, pobre e favelada, além de ser uma criança exausta, é uma criança que se alimenta só de coisas processadas, ou seja, elas são o grande cliente da indústria farmacêutica. Se a gente não emancipar e autonomizar essas crianças pela alimentação, elas que vão manter a indústria farmacêutica, a indústria da doença, a indústria do câncer.

21. Agora... É micro, pode ser inócuo, mas eu não vou embora dessa roda gigante que é essa vida, fazendo alguma coisa que eu fique constrangida. Enquanto inocente no meu constrangimento, aqui eu posso estar criando equívocos, mas na hora que você "toma tento" da coisa, aí acho que é difícil não se mover. Então, a Escola Por Vir também não deixa de ser uma resposta a mim mesma, e uma vontade de "cheguei aqui. Cheguei na Cris. E agora? O que a gente pode alavancar?" Propus para a Cris de fazermos uma escola, vamos fazer uma associação, e ela disse "não. Quero fazer eventos." Legal, acho que também deu uma chave para a Cris. 


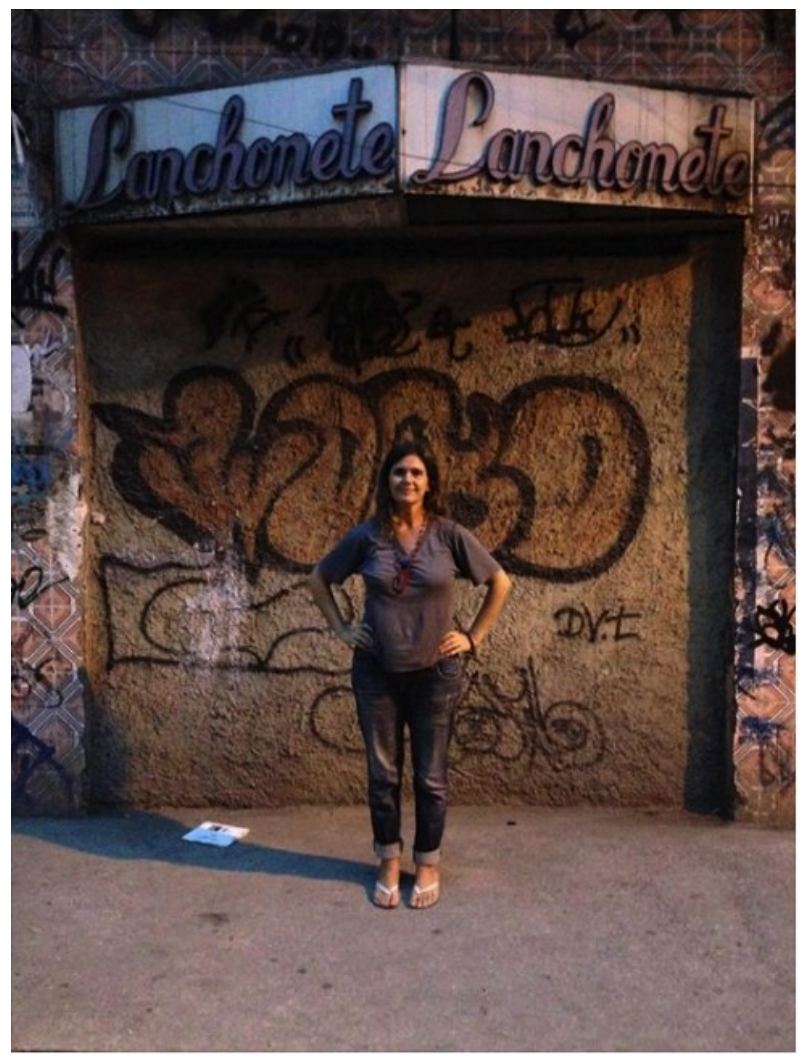




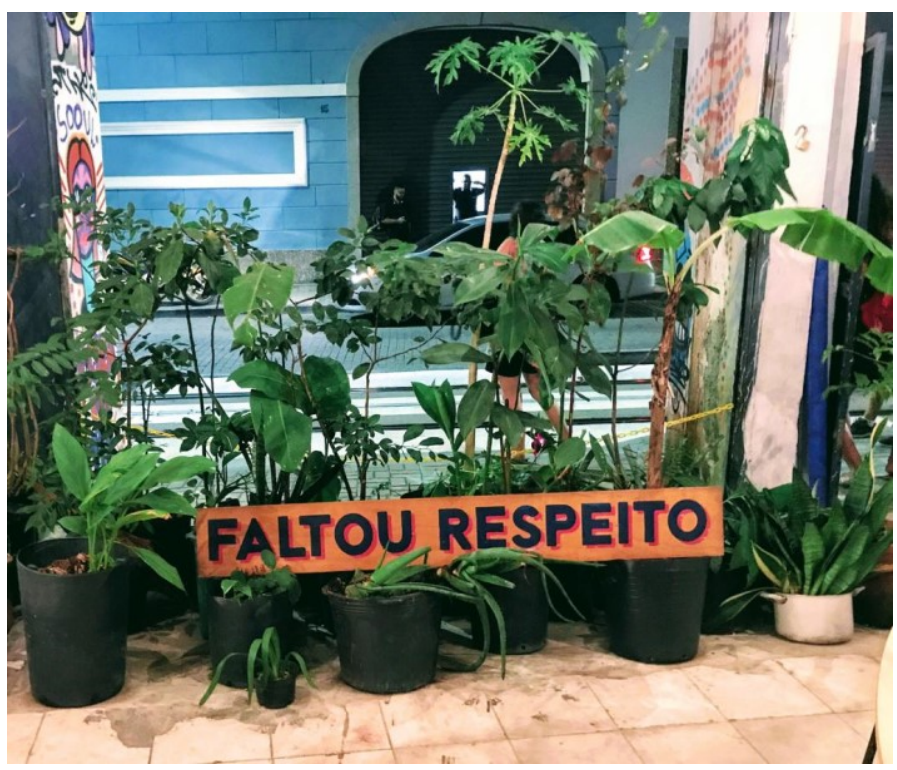

Luiz Guilherme Vergara, Kriss Coiffeur, Ligia Veiga, Thelma Vilas Boas. Escola do mundo: ideias para adiar... 


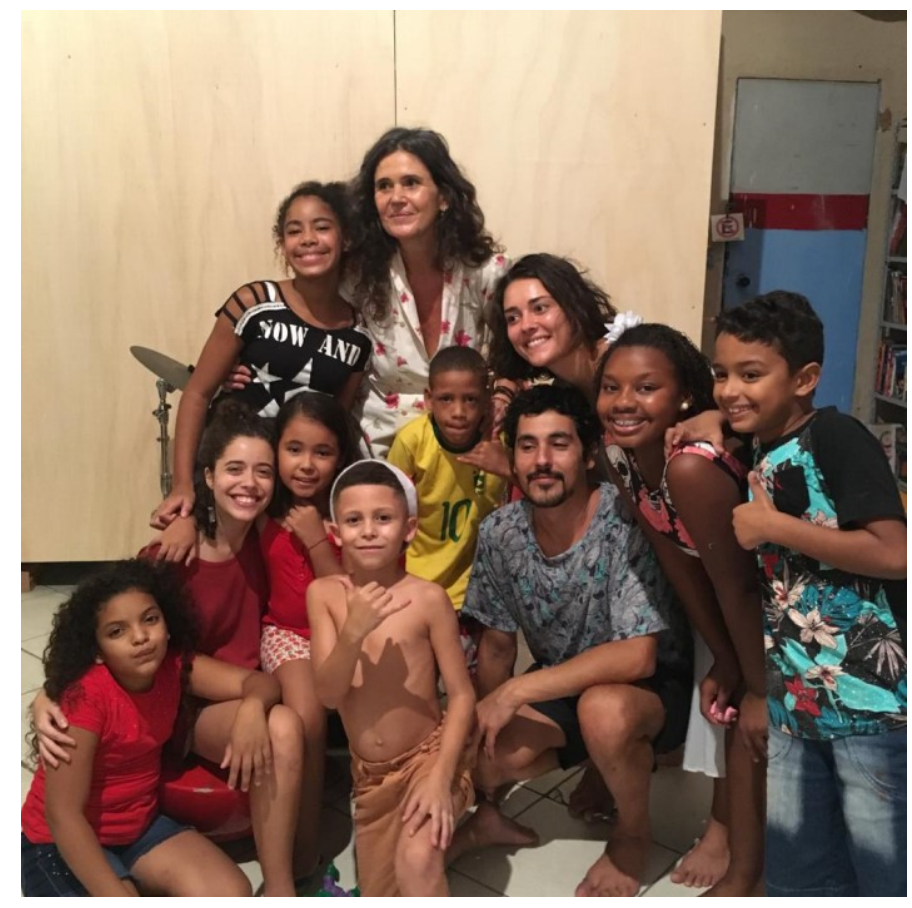


22. A onda que eu achei que ia ser importante acontecer era a gente acolher melhor essas crianças com menos ruído. Que a vida já é tão ruidosa, onde a gente poderia ter um lugar sagrado, que não fosse religioso? Porque as crianças visitam esses espaços que são aparentados do sagrado, na igreja. Não. Que não seja na igreja. Que seja sagrado porque é um lugar que tem essa vibração. Porque tem um sol no centro e porque tem alguém tentando, de alguma maneira, inventar uma escola para os dois lados. Com eles e com os adultos. Por isso é tão importante a presença dos adultos. Que tem sido pouca. Ela acontece em ativações programadas, mas nesse dia a dia, nesse devir do dia a dia de ajudar a melhorar o tecido social, as pessoas estão muito implicadas em outras coisas, em outras coisas também muito legais, mas fazem falta.

\section{Notas}

${ }^{1}$ Relatos-entrevistas com Kriss Coiffeur - Lanchonete <>Lanchonete / Bar Delas; Ligia Veiga - Grande Companhia de Mysterios e Novidades / Escola sem Paredes (http://ciademysterios. com/escola); e Thelma Vilas Boas - Lanchonete <>Lanchonete / Escola Por Vir, com a participação de estudantes do Curso de Graduação em Artes da Universidade Federal Fluminense (Ana Schaefer, Caroline Rocha, Gabrielle Santos, Gabriella Cerqueira, Isabelle Machado, Lívia Estagne, Loren Muniz, Tuka Mello (Maria Antonia Mello), Maria Luiza Carnevali, Victoria Borges, Rai do Vale e Yone Lima) e colaboração especial de Daniela Moreira (Bolsista PIBIC). Imagens: Marília Felippe, Ana Schaefer, Daniela Moreira e Yone Lima. Transcrição da conversa com Thelma Vilas Boas por Rebecca Moure.

${ }^{2}$ Luiz Guilherme Vergara é professor associado do Departamento de Arte e do Programa de Pós-Graduação em Estudos Contemporâneos das Artes da UFF. É cofundador do Instituto MESA e coeditor da Revista MESA. E-mail: luizguivergara@gmail.com. Orcid: https: / /orcid.org/0000-0002-5311-5181

${ }^{3}$ Kriss Coiffeur (Christiane Rodrigues) é proprietário do Bar Delas e foi parceira de Thelma Vilas Boas no projeto Lanchonete <> Lanchonete ao longo de 2018.

${ }^{4}$ Ligia Veiga é fundadora e diretora da Grande Companhia de Mysterios e Novidades. E-mail: producaociademysterios@gmail.com

${ }^{5}$ Thelma Vilas Boas é artista, criadora dos projetos Lanchonete <> Lanchonete e Escola Por Vir. E-mail: thelmavilasboas.lanchonete@gmail.com

${ }^{6}$ Asia Komarova, artista russa, concluiu recentemente o curso de Mestrado no Programa de Pós-Graduação em Estudos Contemporâneos das Artes, sob orientação do Professor Ricardo Basbaum. Título da dissertação: "Como podemos elaborar um desenho comunitário sem estarmos engajados coletivamente?" (Mais informações: www.theoutsidersunion.nl) 